\title{
Decreased G-CSF and IL-3 Production and Gene Expression from Mononuclear Cells of Newborn Infants ${ }^{1}$
}

\author{
MITCHELL S. CAIRO, YU SUEN, EVA KNOPPEL, RICHARD DANA, LINDA PARK. \\ STEVEN CLARK, CARMELLA VAN DE VEN, AND LEONARD SENDER \\ Division of Hematology/Oncology, Children's Hospital of Orange County, Orange, California 92668; Division of \\ Research Immunology and Bone Marrow Transplantation, Childrens Hospital of Los Angeles, Los Angeles, \\ California 90027; Immunex Research and Development Corporation, Seattle, Washington 98101; and Genetics \\ Institute, Cambridge, Massachusetts 02140
}

\begin{abstract}
Newborns are predisposed to neutropenia and thrombocytopenia during bacterial sepsis. The presence of peripheral cytopenias during overwhelming infection may be secondary to decreased hematopoietic growth factor production during states of increased demand. We therefore examined circulating levels of granulocyte-colony stimulating factor (G-CSF) and IL-3, production of G-CSF and IL-3 from unstimulated and stimulated mononuclear cells (MNC), expression of G-CSF and IL-3 genes during unstimulated and stimulated conditions, and equilibrium and binding of G-CSF receptors on mature effector peripheral blood cells of adults and neonates. Serum from cord and adult peripheral blood contained negligible amounts of both G-CSF ( $\leq 50 \mathrm{pg} / \mathrm{mL})$ and IL-3 $(\leq 5 \mathrm{pg} / \mathrm{mL})$. Constitutive supernatant levels of G-CSF and IL-3 from cord and adult unstimulated MNC were also undetectable. However, there was a significant difference in G-CSF and IL-3 production from stimulated cord and adult MNC. Supernatants from stimulated adult $\mathrm{MNC}$ had significantly more G-CSF $(p<0.007)$ and IL-3 $(p<0.02)$. Additionally, Northern blot hybridization and densitometry of autoradiographs demonstrated significantly more G-CSF and IL-3 mRNA transcripts from adult than from cord MNC. Lastly, affinity, binding, and number of G-CSF receptors on cord and adult peripheral effector cells were equal. These data suggest that, during states of increased demand, cord MNC produce less G-CSF and IL-3 than do adult MNC and have an associated reduction in their respective mRNA transcripts. These findings may have implications in the pathogenesis of neonatal cytopenias during states of increased demand, such as sepsis. (Pediatr Res 31: 574 $578,1992)$
\end{abstract}

\section{Abbreviations}

CSF, colony stimulating factor

G-CSF, granulocyte-colony stimulating factor

rhG-CSF, recombinant human granulocyte-colony stimulating factor

MNC, mononuclear cell

Received August 12, 1991; accepted January 24, 1992

Reprint requests: Mitchell S. Cairo M.D., Director, Hematology/Oncology Research and Bone Marrow Transplantation. Children's Hospital of Orange County, 455 S. Main Street, Orange, CA 92668.

Supported in part by grants from the Walden W. and Jean Young Shaw Foundation, the CHOC Research and Education Foundation, and the Pediatric Cancer Research Foundation. 1991
CFU-GM, colony forming unit-granulocyte macrophage PMN, polymorphonuclear cell

During states of increased demand for blood cells, such as during overwhelming bacterial sepsis, newborn infants tend to develop neutropenia because of reduced mature effector neutrophil storage pools, reduced myeloid progenitor pools (CFU-GM), and accelerated steady state myeloid progenitor proliferative rates (1-4). Additionally, neonatal mature effector neutrophils have qualitative deficiencies, especially with respect to chemotaxis, phagocytosis, C3bi receptor expression, and bacterial killing compared with adult neutrophils $(1,5)$. During experimental group B streptococcal sepsis, newborn rats develop profound neutropenia secondary to depletion of bone marrow neutrophil storage pool reserves and reduced proliferation of CFU-GM progenitor pools compared with those of adult animals $(4,6,7)$.

Regulation of hematopoiesis is developmentally immature in the newborn $(8,9)$. The control of hematopoiesis is in part regulated by CSF and IL. G-CSF, a lineage-specific hematopoietic growth factor, stimulates myeloid progenitor proliferation, induces egress of mature neutrophil storage pool cells from the bone marrow into the peripheral blood, and enhances mature neutrophil effector function (10-12). IL-3 is less lineage-specific and stimulates hematopoiesis at an earlier progenitor cell stage, resulting in the formation of multiple lineages, including colony forming unit-granulocyte, erythroid, monocyte, megakaryocyte; CFU-GM; colony forming unit-megakaryocyte; and burst forming unit-erythroid $(13,14)$.

We previously demonstrated that single-pulse administration of rhG-CSF to neonatal rats results in neutrophilia, induces neutrophil proliferative pools, and acts prophylactically or simultaneously with antibiotics to reduce mortality during experimental group B streptococcal infection $(15,16)$. Prolonged administration of rhG-CSF to neonatal rats modulates neonatal myelopoiesis, resulting in neutrophilia, increases marrow neutrophil storage pools, and reduces mortality during experimental group B streptococcal infection (17). Recently, we demonstrated that prolonged administration of recombinant murine IL-3 to newborn rats does not induce neutrophilia, but does increase bone marrow myeloid progenitor pools (18). The present study was undertaken to determine the difference, if any, between human G-CSF and IL-3 production and gene expression from human neonatal and adult peripheral MNC.

\section{MATERIALS AND METHODS}

Isolation of human MNC and PMN. Heparinized venous blood was drawn from normal volunteers in accordance with the 
principles of the Declaration of Helsinki. Venous cord blood was drawn from the umbilical vessels of placentas of normal, fullterm, nonstressed infants immediately after vaginal delivery $(10 \%)$ or scheduled cesarean section without labor $(90 \%)(19$, 20). Six percent Dextran-70 in $0.9 \%$ saline (McGaw Laboratories, Irvine, $\mathrm{CA}$ ) was added to both the cord and donor whole blood samples, and their red blood cells were allowed to sediment. The leukocyte-enriched plasma was collected, layered on a Ficoll-Hypaque gradient $(p=1.077)$, and centrifuged for 30 min. MNC were collected from the Ficoll interface, and PMN cells were recovered in the cell pellet. Any remaining erythrocytes were hemolyzed by hypotonic lysis. Isolated MNC and PMN were then suspended in Dulbecco's (D-PBS), pH 7.4, or PBS, $\mathrm{pH} 7.4$, with $5 \mathrm{mM}$ glucose (PBS-G) at various concentrations depending on particular assay requirements. PMN were $98 \%$ pure in cord and adult preparations by flow cytometry and microscopy. The MNC distribution was similar in both cord and adult preparations (cord: $82 \pm 8.0 \%$ lymphocytes and $8.8 \pm 4.0 \%$ monocytes; adult: $86 \pm 4.0 \%$ lymphocytes and $7.2 \pm 3.0 \%$ monocytes). MNC $\left(1 \times 10^{6}\right)$ from both cord and adults were then stimulated with phorbol 12-myristate 13-acetate $(20 \mathrm{ng} /$ $\mathrm{mL})$ and Phaseolus vulgaris phytohemagglutinin $(2 \mu \mathrm{g} / \mathrm{mL})$ to determine G-CSF production and phorbol 12-myristate 13-acetate $(3 \mathrm{ng} / \mathrm{mL}) \pm 0.5 \mu \mathrm{M}$ A23187 (Sigma Chemical Co., St. Louis, MO) to determine IL-3 production. These stimulants were chosen because they were demonstrated to be the optimal agonists under the described conditions (data not shown). Supernatants were collected at $0,6,24,48$, and $72 \mathrm{~h}$ and frozen at $-70^{\circ} \mathrm{C}$ for future studies.

ELISA for detecting $I L-3$. IL-3 levels from serum and from stimulated and unstimulated MNC supernatants were measured with a sandwich ELISA (Immunex, Seattle, WA). Microtiter plates were coated with a mouse anti-rhuIL-3 MAb overnight at $4^{\circ} \mathrm{C}$ and blocked with nonfat dried milk (Carnation, Los Angeles, $\mathrm{CA}$ ) in PBS. Samples and standards (Genzyme, Boston, MA) were diluted $1: 1$ with $10 \%$ goat serum in PBS, added to the plates, and incubated for $2 \mathrm{~h}$ at room temperature. Plates were washed with $0.05 \%$ Tween-20 (Sigma Chemical Co.) in PBS, and rabbit-anti-mouse rhIL-3 was added and incubated for an additional hour. Plates were again washed, developed with $3,3^{\prime}, 5,5^{\prime}$ tetramethylbenzidine (BioRad Laboratories, Richmond, CA) for $30 \mathrm{~min}$, and read at an OD of $690 \mathrm{~nm}$. All samples were run in triplicate, and the data presented as mean \pm SEM of eight to 10 separate supernate samples per group.

ELISA for detecting human G-CSF. G-CSF levels from serum and from stimulated and unstimulated MNC culture supernatants were measured by a sandwich ELISA assay (Amgen, Thousand Oaks, CA) Briefly, microtiter plates were coated with polyclonal rabbit anti-rhG-CSF Ig, and rhG-CSF standards and test samples were added and incubated at $37^{\circ} \mathrm{C}$ overnight. Horseradish peroxidase-conjugated mouse monoclonal anti-G-GSF antibody was added and incubated for $2 \mathrm{~h}$ at $37^{\circ} \mathrm{C}$. Plates were washed and tetramethylbenzidine was added as the substrate. The reaction was stopped after $30 \mathrm{~min}$ by the addition of sulfuric acid $(0.5 \mathrm{~N})$. OD of the samples was measured at $450 \mathrm{~nm}$ with a BioRad EIA reader. All samples were run in triplicate and the data is presented as the mean $\pm \operatorname{SEM}(n=7)$.

$R N A$ isolation and Northern blotting. Total RNA was extracted from stimulated and unstimulated cells by the method of Chomczynski et al. (21). Cells were collected in a buffer containing guanidinium thiocyanate, sodium citrate, sarcosyl, and mercaptoethanol. Sodium acetate and phenolchloroform were added to the buffer to extract RNA from the DNA and proteins. Samples were then precipitated with isopropanol followed by reprecipitation with ethanol, and contamination of ribonuclease was minimized by dissolving the RNA pellet in $0.5 \%$ SDS. Samples were then added to a loading buffer containing orange $G$ and Ficoll (type 400), heated for $15 \mathrm{~min}$ at $65^{\circ} \mathrm{C}$, and rapidly cooled before the addition of $1 \mu \mathrm{g} / \mathrm{mL}$ ethidium bromide. Samples were run on $1.0 \%$ agarose gel in MOPS buffer \pm formaldehyde at 50
$\mathrm{V}$ overnight. Gels were transferred to nitrocellulose membranes. Filters were baked at $80^{\circ} \mathrm{C}$ for $2 \mathrm{~h}$ and prehybridized in hybridization buffer $(50 \%$ formamide, $5 \% \times$ SSC, $2 \times$ Denhardt's, 50 $\mathrm{mM}$ sodium phosphate, $\mathrm{pH} 6.5,50 \mu \mathrm{g} / \mathrm{mL}$ denatured singlestrand salmon sperm DNA, and $0.1 \%$ SDS). Filters were hybridized for $18 \mathrm{~h}$ in $\mathrm{HB} \pm 10 \%$ dextran sulfate to ${ }^{32} \mathrm{P}$-labeled probes: IL-3 = pHyclL-3-2 (American Type Culture Collection, Rockville, $\mathrm{MD}$ ); G-CSF = human G-CSF cDNA (about $1.8 \mathrm{~kb}$ ) at the XhoI site of the vector $\mathrm{pXM}$ (amp resistant).

Binding of ${ }^{125} I-G-C S F$ to $P M N$. Binding assays were performed by a phthalate oil separation method (22). However, isolated PMN were suspended in a binding medium of RPMI-1640 with $2 \%$ BSA, $20 \mathrm{mM} N$-2-hydroxyethylpiperazine- $N^{\prime}$-2-ethanesulfonic acid buffer, and $0.2 \%$ sodium azide (Sigma Chemical Co.), pH 7.2. Cells were placed in 96-well microtiter plates and incubated with ${ }^{125} \mathrm{I}-\mathrm{G}-\mathrm{CSF}$ (kindly provided by Linda Park, Immunex) in binding medium for $1 \mathrm{~h}$ at $37^{\circ} \mathrm{C}$. Replicate aliquots of cells were then transferred to a precooled phthalate oil mixture of 1.5 parts dibutylphthalate (Kodak, Rochester, NY) and 1 part bis (2-ethylhexyl) phthalate (Kodak), and cell-bound ${ }^{125} \mathrm{I}$-cytokines were separated from unbound ${ }^{125}$ I-cytokine by centrifugation. Radioactivity was measured on an LKB Universal Gamma Counter (Pharmacia, Milwaukee, WI). Nonspecific binding was measured using a 100-fold molar excess of unlabeled G-CSF mixed with radiolabeled G-CSF before the addition of cells. Specific binding is defined as the amount of binding blocked by competition with excess unlabeled cytokines. Data was analyzed by weighted nonlinear least squares curve-fitting developed by Munson and Rodbard (23)

Statistical analysis. Results are expressed as mean values \pm SEM of triplicate tests of three to 10 samples. The probability of significant differences when comparing two groups was determined with the use of the unpaired $t$ test, and the probability of significant differences when examining multiple groups was determined by using the analysis of variance followed by the Student-Newman-Keuls multiple range tests to define the unique subsets within the study. Statistical analyses were performed using the Biostat I statistical program (Sigma Soft, Placentia, CA) for the IBM personal computer. $p$ values $<0.05$ were considered significant.

\section{RESULTS}

Serum G-CSF and IL-3 concentrations from both cord and adult peripheral blood $(n=6)$ were below the limit of our detectability $(<50 \mathrm{pg} / \mathrm{mL}$ for G-CSF and $<5 \mathrm{pg} / \mathrm{mL}$ for IL-3). Positive G-CSF values included serum from 12 patients with neutropenia after bone marrow transplantation (1000-2500 pg/ $\mathrm{mL}$ ) and additionally were obtained by using commercial rhGCSF and recombinant human IL-3 incubated control serum. Constitutive supernatant levels of G-CSF and IL-3 from cord and adult unstimulated MNC were undetectable. There was a significant difference, however, in G-CSF and IL-3 levels obtained from stimulated cord and adult MNC. Maximal stimulation occurred between 48 and $72 \mathrm{~h}$. There was significantly less $\mathrm{G}-\mathrm{CSF}$ at $48(p<0.02)$ and $72 \mathrm{~h}(p<0.007)$ from cord MNC than from adult cells (Fig. 1). Similarly, there was significantly less IL-3 at $24 \mathrm{~h}(p<0.0001), 48 \mathrm{~h}(p<0.003)$, and $72 \mathrm{~h}(p<$ 0.02 ) from stimulated cord MNC than from adult cells (Fig. 2).

Unstimulated (at h 0 ) cord and adult MNC G-CSF mRNA transcripts were undetectable. However, after stimulation, fewer G-CSF mRNA transcripts were detected from cord MNC than from adult cells $(6-24 \mathrm{~h})(n=3)$ (Fig. 3). Similarly, unstimulated (at h 0 ) cord and adult MNC IL-3 mRNA were undetectable, but, upon stimulation, decreased IL-3 mRNA transcripts were detected from stimulated cord versus adult MNC throughout the 24 h of stimulation ( $n=3$ ) (Fig. 4).

Affinity, binding, and G-CSF receptor numbers on cord and adult peripheral effector cells were measured (Fig. 5). The binding curve and Scatchard analysis of cord and adult neutrophil G- 


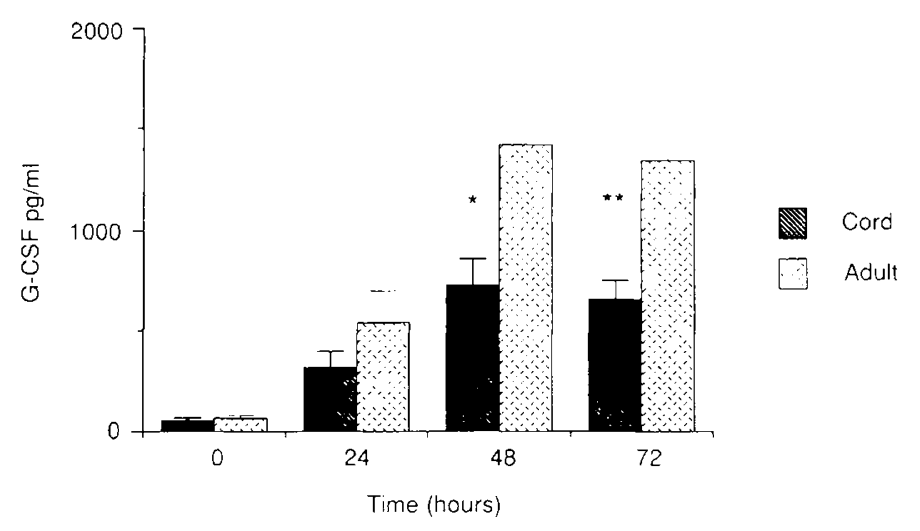

Fig. 1. G-CSF supernatant levels (ELISA) produced from adult and cord MNC $\left(1 \times 10^{6}\right)$ stimulated for $0,24,48$ and $72 \mathrm{~h}$ with phorbol myristate acetate $(20 \mathrm{ng} / \mathrm{mL})$ and phytohemagglutinin $(2 \mu \mathrm{g} / \mathrm{mL})$. Data represents mean \pm SEM of eight to 10 supernatant samples. ${ }^{*}, p<0.02$; $* *, p<0.007$ (cord $v s$ adult).

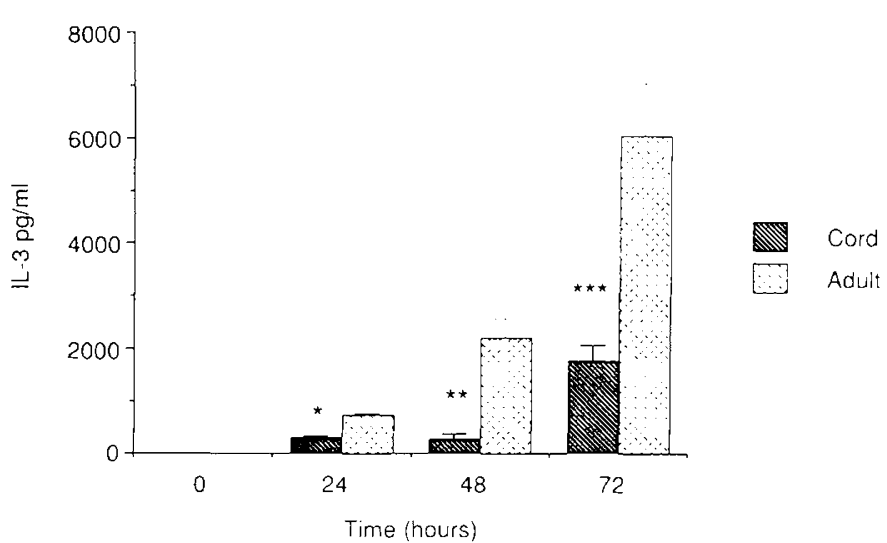

Fig. 2. IL-3 supernatant levels (ELISA) produced from adult and cord MNC $\left(1 \times 10^{6}\right)$ stimulated with phorbol myristate acetate $(3 \mathrm{ng} /$ $\mathrm{mL})$ and A23187 $(0.5 \mu \mathrm{M})$. Data represents mean \pm SEM of seven supernatant samples. ${ }^{*}, p<0.0001 ;{ }^{* *}, p<0.003 ;{ }^{* * *}, p<0.02$ (cord vs adult).

CSF receptors revealed similar affinity and equilibrium curves ( $\mathrm{k}_{\mathrm{d}}: 402 \pm 65$ versus $637 \pm 52 \mathrm{pM}$, cord versus adult $)(p=\mathrm{NS})$. The number of G-CSF receptors was also similar on cord and adult neutrophils $(805 \pm 68$ versus $981 \pm 105$ sites/cell, cord versus adult $)(p=\mathrm{NS})$.

\section{DISCUSSION}

Peripheral neutropenia and thrombocytopenia are characteristic findings during overwhelming bacterial sepsis in the newborn infant and may predict a poor outcome (24). During states of increased demand, such as bacterial sepsis, CSF and IL appear to be the major regulators of increased myeloid and megakaryocyte proliferation and maturation.

Recently, rhG-CSF therapy has been demonstrated to correct the neutropenia in infants and children with congenital agranulocytosis (Kostmann syndrome), reverse cyclic neutropenia in both children and adults, and shorten the period of neutropenia after high-dose multiagent chemotherapy (25-27). IL-3 also induces significant changes in hematopoiesis, both in primates and adults. Recombinant human IL-3 administered in primates induced a significant increase in the circulating white blood cell count, platelet count, and reticulocyte count (28). Recently, IL3 therapy in patients with either advanced malignancy or aplastic anemia has been demonstrated to induce an increase in circulating neutrophils, eosinophils, and platelets $(29,30)$.

Laver et al. (31), using a bioassay, recently reported increased circulating GM-CSF and G-CSF serum levels during steady state

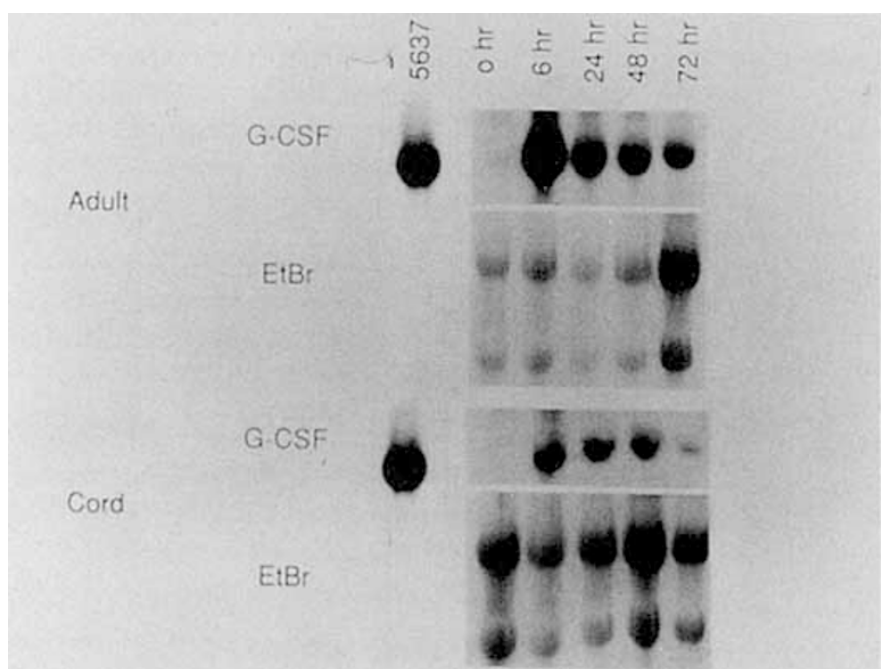

Fig. 3. G-CSF mRNA from unstimulated (at $\mathrm{h}$ 0) and stimulated MNC from cord and adult blood. Cells were isolated, stimulated with phorbol myristate acetate $(20 \mathrm{ng} / \mathrm{mL})$ and PHA $(2 \mu \mathrm{g} / \mathrm{mL})$, and RNA was extracted. The Northern blot was hybridized with ${ }^{32} \mathrm{P}$-labeled G-CSF probe (G-CSF cDNA). 5637 is a human bladder carcinoma cell line serving as a positive control for $\mathrm{G}-\mathrm{CSF}(n=3)$. Ethidium bromide $(E t B r)$ stain was used to determine that the amount of RNA deposited on the gel was equal throughout.

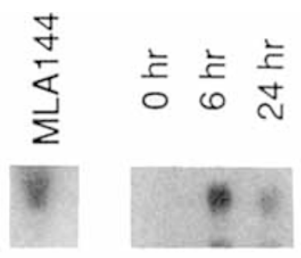

Adult

$\mathrm{EtBr}$
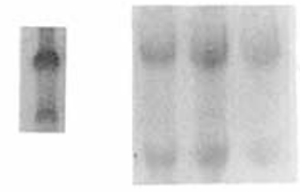

IL-3

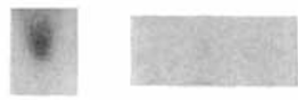

Cord

$\mathrm{EtBr}$

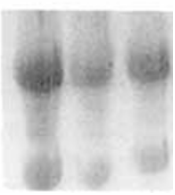

Fig. 4. IL-3 mRNA from unstimulated (at h 0 ) and stimulated MNC from cord and adult blood. Cells were isolated, stimulated with phorbol myristate acetate $(3 \mathrm{ng} / \mathrm{mL})$ and A23 $187\left(10^{-8} \mathrm{M}\right)$, and RNA was extracted. The Northern blot was hybridized with ${ }^{32} \mathrm{P}$-labeled IL-3 probe (pHuclL33-2). MLAI44 is a gibbon lymphoma cell line serving as a positive control for IL-3 $(n=3)$. Ethidium bromide $(E t B r)$ stain was used to determine that the amount of RNA deposited on the gel was equal throughout.

conditions from cord compared with adult peripheral blood. When they used an anti-G-CSF MAb, a $28 \%$ residual activity remained, suggesting that other growth factors may be influencing the results of their bioassay. Serum levels of G-CSF and IL3 measured by an immunologic assay, however, may not correlate completely with biologic activity. Our results, using a specific ELISA assay, demonstrated negligible circulating G-CSF levels 

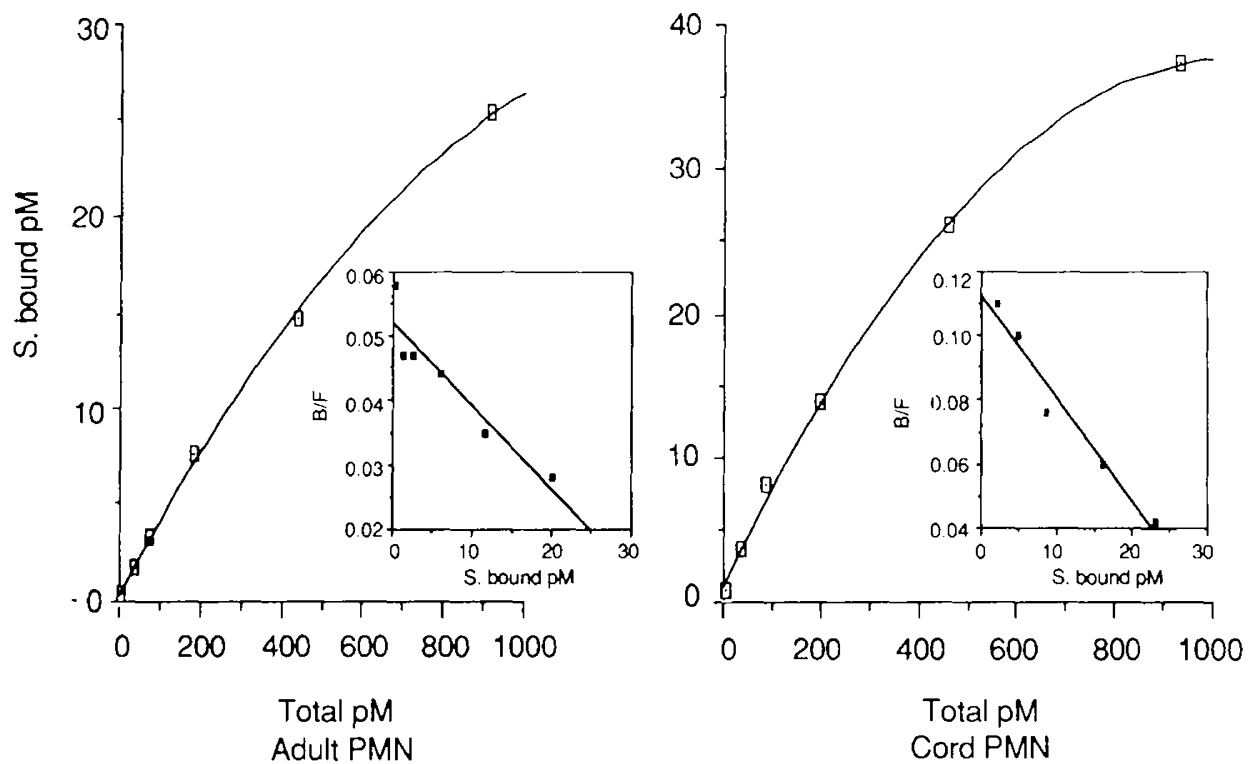

Fig. 5. Specific binding of ${ }^{125}$ I-labeled G-CSF to PMN from cord and adult peripheral blood. The amount of nonspecific binding not blocked by competition with a 100 -fold excess of unlabeled G-CSF was substrated from the total binding. Insert, Scatchard analysis of the equilibrium binding data.

in both cord and adult serum. Additionally, during states of inactivation, supernatants from peripheral $\mathrm{MNC}$ from both cord and adult had negligible amounts of G-CSF. Similarly, our study has shown negligible amounts of circulating IL-3 in the serum of cord and adult peripheral blood; constitutive supernatant levels of IL-3 were also undetectable. However, during specific agonist stimulation, there was a significant difference in both $\mathrm{G}$ CSF and IL-3 production by cord and adult MNC.

Although the present study demonstrated decreased G-CSF and IL-3 production from stimulated cord versus adult MNC, total neonatal G-CSF and IL-3 production may be somewhat different because of our inability to measure these cytokines from other sources, such as endothelial cells and fibroblasts. Additionally, our study did not determine whether the decrease in GCSF or IL-3 production from cord MNC was secondary to a decrease per MNC or a decrease in the specific subpopulation of G-CSF and IL-3 producing MNC. These results are consistent with our previous findings demonstrating negligible amounts of cord serum GM-CSF and decreased GM-CSF production after stimulation of cord MNC (32).

Analysis of G-CSF and IL-3 mRNA expression from cord MNC by Northern blot hybridization confirms negligible G-CSF and IL-3 mRNA expression during constitutive or resting conditions. However, upon stimulation of cord MNC, there was a significant reduction in G-CSF mRNA transcript expression during the entire 24 -h period of stimulation and barely detectable IL-3 mRNA transcript expression during a similar time period. This reduced CSF mRNA transcript expression is similar to that in our previous studies analyzing the regulation of GM-CSF mRNA between cord and adult MNC (32).

We have previously analyzed the mechanisms associated with decreased GM-CSF mRNA expression from stimulated cord MNC. Nuclear run-on transcriptional events and actinomycin $D$ half-life studies (posttranscriptional events) have suggested reduced stabilization of GM-CSF $m$ RNA and reduced GM-CSF mRNA half-life (32). The decrease in G-CSF and IL-3 protein production and mRNA expression from cord MNC may be secondary to a similar mechanism such as the previously described dysregulation of cord MNC GM-CSF, but further studies are needed to corroborate this. Reduced G-CSF and IL-3 mRNA message during states of activation may lead to decreased cytokine production during overwhelming stress, precipitating peripheral neutropenia and a subsequent increase in morbidity. Further studies are needed to test this hypothesis.
We conclude that serum and constitutive supernatant levels of G-CSF and IL-3 are negligible and undetectable in cord and adult peripheral blood. However, during states of increased demand (i.e. after agonist stimulation), there is significantly less GCSF and IL-3 production by neonatal than adult MNC. The clinical significance of this reduction of G-CSF and IL-3 remains to be determined. The affinity and the number of G-CSF receptors on cord and adult peripheral effector cells, however, were similar. Reduced G-CSF and IL-3 production during states of increased demand may play a role in the pathogenesis of neutropenia and thrombocytopenia that occurs during bacterial infection in the newborn. Further studies are needed to assess the relationship of the present findings with the abnormalities observed during overwhelming bacterial sepsis.

Acknowledgment. The authors thank Linda Rahl for her editorial assistance in the preparation of this manuscript.

\section{REFERENCES}

1. Cairo MS 1989 Neonatal neutrophil host defense. Am J Dis Child 143:40-46

2. Christensen R, Rothstein G 1984 Pre- and postnatal development of granulocyte stem cells (CFUc) in the rat. Pediatr Res 18:599-602

3. Erdman SH, Christensen RD, Bradley PP, Rothstein G 1982 Supply and release of storage neutrophils: a developmental study. Biol Neonate 41:132137

4. Christensen RD, Macfarlane JL, Taylor NL, Hill HR, Rothstein G 1982 Blood and marrow neutrophils during experimental group $\mathrm{B}$ streptococcal infection: quantification of the stem cell, proliferative, storage and circulating pools. Pediatr Res 16:549-553

5. Hill JR 1987 Biochemical, structural and functional abnormalities of polymorphonuclear leukocytes in the neonate. Pediatr Res 22:375-382

6. Christensen R, Hill H, Rothstein G 1983 Granulocytic stem cell (CFU-C) proliferation in experimental group B streptococcal sepsis. Pediatr Res 17: 278-280

7. Christensen R, Shigeoka A, Hill H, Rothstein G 1980 Circulating and storage neutrophil changes in experimental type II group B streptococcal sepsis. Pediatr Res 14:806-808

8. Christensen R 1989 Hematopoiesis in the fetus and neonate. Pediatr Res $26: 531-535$

9. Nathan D 1990 Regulation of hematopoiesis. Pediatr Res 27:423-43

10. Welte K, Platzer E, Lu L, Gabrilove J, Levi E, Mertelsmann R, Moore M 1987 Purification and biochemical characterization of human pluripotent hematopoietic colony-stimulating factor. Proc Natl Acad Sci USA 82:1526-1530

11. Ulich T Del Castillo J Souza L 1988 Kinetics and mechanisms of recombinan human granulocyte-colony stimulating factor-induced neutrophilia. Am J Pathol 133:630-638

12. Lopez A, Nicola N, Burgess A, Metcalf D, Battye F, Sewell W, Vadas M 1983 Activation of granulocyte cytotoxic function by purified mouse colonystimulating factors. J Immunol 131:2983-2988 
13. Yang $Y$, Ciarletta A, Temple $P$, Chung $M$, Kovacic S, Witek-Giannotti J Leary A, Kriz R, Donahue R, Wong G, Clark S 1986 Human interleukin-3 (multi-CSF): identification by expression cloning of a novel hematopoietic growth factor related to murine IL-3. Cell 47:3-10

14. Kannourakis G, Johnson G 1990 Proliferative properties of unfractionated, purified, and single cell human progenitor populations stimulated by recombinant human interleukin-3. Blood 75:370-377

15. Cairo M, van de Ven C, Mauss D, Kommareddy S, Norris K, Sheikh K Modanlou H 1991 Modulation of neonatal rat myeloid kinetics resulting in peripheral neutrophilia by single pulse administration of rh granulocytemacrophage colony-stimulating factor and rh granulocyte colony-stimulating factor. Biol Neonate 59:13-21

16. Cairo M, Mauss D, Kommareddy S, Norris K, van de Ven C, Modanlou H 1990 Prophylactic or simultaneous administration of recombinant human granulocyte colony stimulating factor in the treatment of group B streptococcal sepsis in neonatal rats. Pediatr Res 27:612-616

17. Cairo M, Plunkett J, Mauss D, van de Ven C 1990 Seven-day administration of recombinant human granulocyte colony-stimulating factor to newborn rats: modulation of neonatal neutrophilia, myelopoiesis, and group B streptococcus sepsis. Blood 76:1788-1794

18. Cairo M, Mauss D, Plunkett J, Gillis S, van de Ven C 1991 Modulation of neonatal myelopoiesis in newborn rats after 7 days' administration of either granulocyte-monocyte colony stimulating factor or interleukin-3. Pediatr Res 29:504-509

19. Boyum A 1968 Isolation of leukocytes from human blood. Scand J Clin Lab Invest 21(suppl 97):77-80

20. Boxer L, Yoder M, Bonsi B, Schmidt M, Ho P, Jersild R, Baehner R 1979 Effects of chemotactic factor, $\mathrm{N}$-formyl-methionyl-leucyl-phenylalanine on adherence and micro-tube assembly of human polymorphonuclear leukocytes. J Lab Clin Med 93:506-510

21. Chomczynski P, Sacchi N 1987 Single-step method of RNA isolation by acid guanidinium thiocyanate-phenol-chloroform extraction. Anal Biochem 162 : 156-159

22. Park L, Friend D, Gillis S, Urdal D 1986 Characterization of the cell surface receptor for granulocyte/macrophage colony-stimulating factor. J Biol Chem 261:4177-4183
23. Munson P, Rodbard D 1980 Ligand: a versatile computerized approach for characterization of ligand-binary systems. Anal Biochem 107:220-239

24. Manroe B, Rosenfeld C, Weinberg A, Browne R 1977 The differential leukocyte count in the assessment and outcome of early-onset neonatal group B streptococcal disease. J Pediatr 91:632-638

25. Bonilla M, Gillio A, Ruggeiro M, Kernan N, Brochstein J, Abboud M, Fumagalli L, Vincent M, Gabrilove J, Welte K. Souza L, O'Reilly R 1989 Effects of recombinant human granulocyte colony-stimulating factor on neutropenia in patients with congenital agranulocytosis. $\mathrm{N}$ Engl $\mathrm{J}$ Med 320:1574-1580

26. Hammond W, Price T, Souza L, Dale D 1989 Treatment of cyclic neutropenia with granulocyte colony-stimulating factor. N Engl J Med 320: 1306-1311

27. Gabrilove J, Jakubowski A, Scher H, Sternberg C, Wong G, Grous J, Yagoda A, Fain K, Moore M, Clarkson B, Oettgen H, Aiton K, Welte K, Souza L 1988 Effect of granulocyte colony-stimulating factor on neutropenia and associated morbidity due to chemotherapy for transitional-cell carcinoma of the urothelium. N Engl I Med 318:1414-1422

28. Mayer P, Valent P, Schmidt G, Liehl E, Bettlheim P 1989 The in vivo effects of recombinant human interleukin-3: demonstration of basophil differentiation factor, histamine-producing activity, and priming of GM-CSF-responsive progenitors in nonhuman primates. Blood 74:613-621

29. Ganser A, Lindemann A, Seipelt G, Ottmann O, Herrmann F, Eder M, Frisch J, Schulz G, Mertelsmann R. Hoelzer D 1990 Effects of recombinant human interleukin-3 in patients with normal hematopoiesis and in patients with bone marrow failure. Blood 76:666-676

30. Ganser A, Lindemann A, Seipelt G, Ottmann O, Eder M, Falk S, Herrmann $F$, Kaltwasser J, Meusers P, Klausmann M, Frisch J, Schulz G, Mertelsmann R, Hoelzer D 1990 Effects of recombinant buman interleukin-3 in aplastic anemia. Blood 76:1287-1292

31. Laver J, Duncan E, Abboud M 1990 High levels of granulocyte and granulocyte-macrophage colony-stimulating factors in cord blood of normal fullterm neonates. J Pediatr 116:627-632

32. Cairo M, Suen Y, Knoppel E, van de Ven C, Nguyen A, Sender L 1991 Decreased stimulated GM-CSF production and GM-CSF gene expression but normal numbers of GM-CSF receptors in human term newborns compared with adults. Pediatr Res 30:362-367 